\title{
"Market expectation shifts in option-implied volatilities in the US and UK stock markets during the Brexit vote"
}

\begin{tabular}{ll} 
& $\begin{array}{l}\text { Artem Bielykh } \\
\text { Sergiy Pysarenko (D) } \\
\text { Dong Meng Ren } \\
\text { Oleksandr Kubatko (D) }\end{array}$ \\
& $\begin{array}{l}\text { Artem Bielykh, Sergiy Pysarenko, Dong Meng Ren and Oleksandr Kubatko } \\
(2021) \text {. Market expectation shifts in option-implied volatilities in the US and UK } \\
\text { stock markets during the Brexit vote. Investment Management and Financial } \\
\text { Innovations, 18(4), 366-379. doi:10.21511/imfi.18(4).2021.30 }\end{array}$ \\
\hline ARTICLE INFO & http://dx.doi.org/10.21511/imfi.18(4).2021.30 \\
\hline DOI & Friday, 24 December 2021 \\
\hline RELEASED ON & Saturday, 16 October 2021 \\
\hline RECEIVED ON & Wednesday, 15 December 2021 \\
\hline ACCEPTED ON & This work is licensed under a Creative Commons Attribution 4.0 International \\
\hline LICENSE & License \\
\hline JOURNAL & "Investment Management and Financial Innovations" \\
\hline ISSN PRINT & $1810-4967$ \\
\hline ISSN ONLINE & $1812-9358$ \\
\hline PUBLISHER & LLC "Consulting Publishing Company "Business Perspectives" \\
\hline FOUNDER & LLC “Consulting Publishing Company "Business Perspectives" \\
\hline
\end{tabular}

NUMBER OF REFERENCES

32

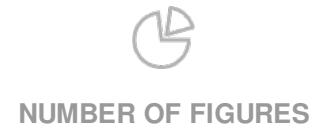

2
NUMBER OF TABLES

5

(C) The author(s) 2021. This publication is an open access article. 


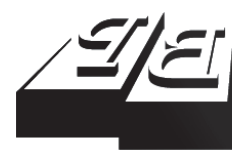

\section{BUSINESS PERSPECTIVES}

9

LLC "CPC "Business Perspectives" Hryhorii Skovoroda lane, 10, Sumy, 40022, Ukraine www.businessperspectives.org
Received on: $16^{\text {th }}$ of October, 2021 Accepted on: $15^{\text {th }}$ of December, 2021 Published on: $24^{\text {th }}$ of December, 2021

C Artem Bielykh, Sergiy Pysarenko, Dong Meng Ren, Oleksandr Kubatko, 2021

Artem Bielykh, M.A. in Economics, Kyiv School of Economics, Ukraine.

Sergiy Pysarenko, Ph.D. in Economics, Assistant Professor of Economics and Finance, Shannon School of Business, Cape Breton University, Canada; Adjunct Professor, Lang School of Business, University of Guelph, Canada (Corresponding author)

Dong Meng Ren, Ph.D. in Economics, Assistant Professor of Economics and Finance, Shannon School of Business, Cape Breton University, Canada.

Oleksandr Kubatko, Doctor of Economics, Dr.Sc., Professor Department of Economics, Entrepreneurship and Business Administration, Sumy State University, Ukraine.

This is an Open Access article, distributed under the terms of the Creative Commons Attribution 4.0 International license, which permits unrestricted re-use, distribution, and reproduction in any medium, provided the original work is properly cited.

Conflict of interest statement: Author(s) reported no conflict of interest
Artem Bielykh (Ukraine), Sergiy Pysarenko (Canada), Dong Meng Ren (Canada), Oleksandr Kubatko (Ukraine)

\section{MARKET EXPECTATION SHIFTS IN OPTION-IMPLIED VOLATILITIES IN THE US AND UK STOCK MARKETS DURING THE BREXIT VOTE}

\section{Abstract}

This paper investigates the effect of the Brexit vote on the connection between UK stock market expectations and US stock market returns. To gauge UK stock market expectations, the option-implied volatilities of the FTSE 100 index are calculated in the period starting five months before and ending four months after the Brexit referendum. To keep the analysis "clean", it stops right before the 2016 US presidential elections. It uses an OLS regression to estimate the change in the relationship between US and UK stock market expectations.

The main findings show that the US and UK stock markets became somewhat less integrated four months after the Brexit referendum compared to the five months before it. The S\&P 500 Index returns have a statistically significant impact on implied volatilities of the FTSE 100 only before the Brexit referendum. However, the British risk-free rate (LIBOR) became a statistically significant factor affecting FTSE 100 implied volatilities only after Brexit. This analysis may be used by decision-makers in the money management industry to act appropriately during Black Swan events. When UK citizens unexpectedly voted in favor of Brexit, the risk-free rate dropped, making it cheaper to invest, increasing the Sharpe ratios of equity portfolios. Coupled with increased uncertainty, this caused portfolio reallocations. In turn, expected volatility measured by options-implied volatility increased.

\section{Keywords} stock exchange, Brexit referendum, financial modeling, option-implied volatilities

\section{JEL Classification G11, G14, G15, F36}

\section{INTRODUCTION}

Once in a while, significant and unexpected events impact financial markets. Over the last five years, there have been three such events: a positive British Exit (Brexit) referendum, elections of Donald J. Trump as a President of the USA, and the COVID 19 pandemic. This study examines the British Brexit referendum, which was held on June 23, 2016. Out of the array of possible questions, one is whether the linkage between the US and UK stock market expectations was changed as measured by the implied-option volatilities.

One can answer this question using option price distributions, which give us the possibility to extract the expectation as implied volatility (IV) and run a regression to estimate the changes in the connection between the two markets. Using implied volatility as a dependent variable, one can answer whether there is a change in the relationship between two markets and see how they can influence each other.

A few authors (Konstantinidi et al., 2008; Gemmill \& Kamiyama, 2000; Mixon, 2002; Glatzer \& Scheicher, 2003) studied the relation- 
ship between asset prices and macroeconomic events using option-implied volatilities. A change in implied volatilities could give us an idea of market expectations for the asset in the future. The first goal of this study is to generate the option-implied volatilities that characterize market expectations before and after the Brexit referendum on June 23, 2016. The secondary goal of the study is to verify whether there was a change in option-implied volatilities of the FTSE 100 Index before and after the Brexit referendum.

The Literature review section shows a gap in the literature between existing findings on option-implied volatilities and Brexit effects on financial markets and economy. The regression is shown in the Methodology section. To perform analysis, the study uses daily data (181 observation days) on options for the period from February 2016 to October 2016, S\&P 500 Index daily returns, exchange rates between the Great British Pound and the United States Dollar (GBP/USD), LIBOR as the risk-free rate, VIX or the Volatility Index of the US stock market, the yield spreads between 10-Y and 1-Y yields of the US Treasury government bonds. It takes four months before Brexit and four months after Brexit. This period represents the time of uncertainty of the British economy due to the result of the Brexit referendum. It ends before the shock associated with the results of the US presidential elections on November 8, 2016. The Results section shows that there was a significant shift in market expectations as measured by option-implied volatilities. The Conclusion section provides more explanations and ideas for future research.

\section{LITERATURE REVIEW}

Investors and policymakers study financial derivatives because they contain rich information on markets' movement expectations. In addition, each of the derivatives can be exposed to primary or underlying instruments, called base ones. In the role of the base, instruments may be various financial instruments or indices. The most well-known are securities, interest rates, exchange rates, stock indices, commodities, credit risks, etc. In this paper, the base one is the FTSE 100 Index, which has kinds of derivatives such as options. Options give the holder the right to buy or sell the asset for a certain time by a certain price (Hull, 2003). The alternative is a derivative instrument that enables hedging against possible losses resulting from fluctuations in the price of the subject of the transaction. There is a division between US options and European options. US options are exercised to acquire or sell the underlying instrument, at a predetermined price, at any time during the option period before its expiration (Eter Carr et al., 1995). European options are exercised often on expiration day (Aguilar \& Korbel, 2019; Aguilar et al., 2021). Between the exercise price and price when the option is brought, there is a range of many possible underlying asset prices. It is used in European style options of FTSE 100.

It is known that such a great event, like Brexit referendum, may have an impact not only on the
British economy (Ramiahm et al., 2017) or the EU economy (De Ville \& Siles-Brügge, 2019), but on the global economy as well (Hassan et al., 2019). Also, there is an anticipated effect of the Brexit vote on financial markets (Hohlmeier \& Fahrholz, 2018) and specifically on the UK stock market (Shahzad et al., 2019). In addition, there were papers that estimated the effect of Brexit on the Indian stock market (Sathyanarayana \& Gargesha, 2016). The uncertainty associated with the United Kingdom departing from the European Union may cause an increase in volatility in the financial markets and selected stock exchange indices (Kurecic \& Kokotovic, 2018). Brexit could have a disastrous effect either on global or internal needs. An escape from the British pound would strengthen the other currencies. One of them is the US dollar, which is the main international currency in the world. That is why it is a mistake to believe that the consequences of Brexit will be limited only to Great Britain and Europe, and will bypass the US. Since the US stock market is the largest in the world, Brexit may have a significant effect on it. In the paper, it is assumed that there is a connection between the UK and US markets. If the change will have statistically significant values, it means there is a strong effect. To be clear, the "connection" is the statistically significant effect of the US stock market on the UK stock market. It is considered that FTSE 100 Index represents the UK stock market, and S\&P 500 represents the US stock market. This change in the connection between the two markets can be interesting for investors 
who expect future changes in the market associated with the great event, which is expected to exist in the future. Knowing market expectations about the connection of the two markets, investors may use this information in their investment decisions to make a profit on market movements. Since the Brexit referendum is an unusual global event and the global economy is becoming more and more integrated with each other, this study may shed light on the change in the connection between the two markets.

Financial decision-makers, in order to achieve efficiency, pay attention to the forecasting object identification, indicators' selection peculiarities, data collection possibilities, and the choice of appropriate methods of financial modeling (Kartanaite et. al., 2021). Thus, recently, many techniques have been developed to use option prices to estimate future financial asset prices and extract the distribution of market expectations. Several authors (Mixon, 2002; Neuhaus, 1995; Pysarenko et al., 2019) focus on the determinants of market movements. In general, volatility is a measure of uncertainty about future changes in the price of a financial instrument. If volatility increases, the probability that a given financial instrument will significantly change its price in the future increases too. This can be both advantageous and unfavorable, from the holder's point of view of such an instrument. The implied volatility is an indicator of market participants' expectations regarding changes in the share price over the year. The IVs are able to incorporate an extensive variety of future scenarios that are not captured by the usage of other historical data. Option IVs are much more sensitive and respond more accurately to changes in market expectations (Hull, 2003). Any shift in beliefs caused by political declaration or new financial information can be captured in the option-implied volatilities. The option prices of assets allow us to extract the IVs using daily data for a constant time horizon. It helps to estimate the period of time that considers past reactions and predicts future market movement expectations. Also, using a short period of time, IVs make it possible to investigate a day-to-day market expectation and help make the decisions faster than more complicated models. The IVs embody an information set that includes many important features that describe data distribution. Expected variance (asset volatility) shows whether the distribution is spread out or concentrated near the mean. Bigger variance means lower certainty of asset stability. Using IV of the distribution investigates the impact of macroeconomic and financial events on densities of stock market expectations.

There is a rich literature on the estimation of the option values (Boyle \& Ananthanarayanan, 1977; Volk-Makarewicz et al., 2021). Many investigators - statisticians, econometrics, theoreticians, and practitioners of financial management - have dealt with the problem of option pricing. To understand the option-implied volatilities, one needs to understand the theory, which is a basis for the options. Among the first pioneers in option pricing theory were Black and Scholes in 1973. They were the first to estimate the fair value of European-style options. They use six variables for option pricing: option type, underlying stock price, time, volatility, strike price, and the risk-free rate. In practice, in addition to listed variables, expectation about the future option price plays an important role in determining the option price. Variability is a parameter that could positively affect the option value. This can be explained by the fact that it measures the risk of the underlying instrument price and, therefore, the options risk (Czech, 2019). The higher the risk, the more the option buyer pays for the option. Hence the value of options goes up as volatility increases. This model (option pricing theory) assumes the underlying asset price evolves due to a stochastic process, known as geometric Brownian motion (GBM), in which instantaneous drift and volatility are constant (Bahra, 1997). It means the implied volatility should be the same for all instruments of the underlying asset; however, there should be different expires and strikes.

The authors (Cox et al., 1976) continue to develop the Black-Scholes model and show that the price of an option is the discounted risk-neutral expected value of the payoffs. This parameter approximating method assumes a particular functional form's risk-neutral probability density function. Parameter values may be found by minimizing part of the fitted price errors. According to the option pricing concept proposed by Cox et al. (1976), the option price can be determined as the discounted cash flow value of the option for assets with the same volatility as the assets to which the 
option is valued and a rate of return equal to the risk-free rate. If the option is valued in accordance with this rule, it is not possible to obtain arbitrage profits. Both approaches lead to the same option price, assuming that the logarithmic rate of return on assets has a normal probability distribution. It should be noted that the option price does not depend on the rate of return on assets for which it is issued but on the risk-free rate and the volatility of the return on assets.

The formula used to estimate the implied volatility is the standard Black-Scholes formula, which was shown earlier. The method used to derive IV is to determine a value such that the squared loss function between observed price and calculated BlackScholes price is zero. To do this, one can use the Newton-Raphson method (Hull 2003).

Konstantinidi et al. (2008) determine the implied volatility (IV) as an instrument to measure market risk to maximize expected returns. Understanding the variation of the IV, market anticipations are formed on how the expected returns change over time. In other words, when the market participants assume the direction of change in implied volatility, they can improve their strategies in the stock market. That is why IVs are often used in trading strategies and considered in managing an investment portfolio. Konstantinidi et al. (2008) study the determinants that significantly affect IV's prediction. ARIMA, AR (1), VAR, ARFIMA are used as the models to forecast IV.

Mixon (2002) studies determinants that explain the change in the implied volatility. The key finding is that an increase in short rates leads to a decrease in the volatility, and vice versa. The volatility of options with 2-3-month maturity increases if the index price decreases. In this case, if volatility and uncertainty increase after the FTSE 100 Index becomes riskier, investors would invest less in the nearest future. Since it is assumed that the US market is dominant in the stock market, it means that the largest share of US investors would abstain from investment in the UK market.

As the literature review shows, on one the hand, there is a wealth of knowledge of effects of the Brexit on the US and UK economies and financial markets, and on the other hand, there are well-established methods relying upon option-implied volatilities and market expectations. However, the gap in the literature is to investigate the effect of the UK/US market connection using option-implied volatilities. Thus, the main research goal is to check whether the connection between the UK and US markets changes before and after the Brexit referendum.

The null hypothesis $\left(H_{0}\right)$ of the study is no change in the connection between the two markets after the Brexit referendum. The alternative hypothesis $\left(H_{1}\right)$ is that there is a change in the connection between the two markets after the Brexit referendum. This means that the US market does have a statistically significant effect on the UK stock market after the Brexit referendum.

\section{METHODOLOGY}

The methodology of the study is structured in three stages: First, the data from Bloomberg Terminal, which gives access to the database from the London Stock Exchange and the CBOE, are obtained. The data is cleared to have clear data for estimations. Second, implied volatilities are estimated from the options of the FTSE100 Index. It estimates market expectations about future stock market movements before and after the Brexit referendum. Third, the change in the connection between two markets before and after the Brexit referendum is assessed by estimating the regression using a dummy variable. The dummy variable is a key indicator that shows this change.

The whole database includes FTSE 100 Index close prices, call options premiums, option strike prices, days to maturity, and the risk-free rate (LIBOR). It is a filtred database in order to have clear data with no omitted values. The data consist of 181 trading days from February till October 2016. Weekends and holidays are discarded from the sample. The set of all available call options prices is chosen with a horizon of up to 9 months - the research period. Every options contract expired every third Friday of each month. The same criteria were used by Glatzer and Scheicher (2003).

When the entire sample is ready, the "at-the-money" strike prices that are closest to the underlying asset price for each day are selected. "At-the- 
money" is the situation when the current strike options price is the same as the underlying asset price. Most investors focus on this value, thus there is the lowest volatility at this price. It is important because there is no intrinsic value and it may have time value (amount of time that remains until the options contract expiration). So when "at-the-money" is taken as the option strike price, there is only one strike price for one corresponding day.

The formulas (1) - (4) used to estimate the implied volatility is based on the standard Black-Scholes formula (Wu, 2004; Karoui et al., 1998; Butler \& Schachter, 1986):

$C_{t}=S_{0} e^{-\delta(T-t)} \Phi\left(d_{1}\right)-K e^{-r_{f}(T-t)} \Phi\left(d_{2}\right)$.

$P_{t}=K e^{-r_{f}(T-t)} \Phi\left(-d_{2}\right)-S_{0} e^{-\delta(T-t)} \Phi\left(-d_{1}\right)$.

$d_{1}=\frac{\ln \left(\frac{S_{0}}{K}\right)+\left(r+\frac{\sigma^{2}}{2}\right) T}{\sigma \sqrt{T}}$.

$d_{2}=\frac{\ln \left(\frac{S_{0}}{K}\right)+\left(r-\frac{\sigma^{2}}{2}\right) T}{\sigma \sqrt{T}}=d_{1}-\sigma \sqrt{T}$.

where $C_{t}$ - call option price at time $t \in[0, \mathrm{~T}], P_{t}$ - put option price at time $t \in[0, T], T$ - exercise time of an option, $t$ - observed time, $K$ - strike price, $\Phi(x)$ - cumulative probability density function for a standardized normal distribution, $S_{0}$ underlying asset price at time zero, $r$ - risk-free interest rate, and $\sigma$ - expected volatility of an underlying asset.

The method used to derive IV is to determine a value such that the squared loss function between observed price and calculated Black-Scholes price is zero. To do this, the Newton-Raphson method is used (Garrett, 2015).

The software used to estimate IVs, is MATLAB, and its Financial Toolbox. The variables used to estimate IVs are as follows:

- $\quad$ strike option price;

- $\quad$ underlying asset price (FTSE 100 Index price);
- $\quad$ risk-free interest rate (LIBOR);

- time to maturity expressed on an annual basis; and

- call European option price

For now, implied volatilities are obtained for each trading day with corresponding variables.

The following key variables of the regressions are:

- change in implied volatility $(\Delta \mathrm{IV})$ is estimated in (5);

- risk-free rate $(\Delta \mathrm{RF})$ as LIBOR;

- exchange rate ( $\Delta \mathrm{EX})$ of GBP/USD, $\Delta$ VIX;

- the US slope yield curve (USSL);

- $\quad$ S\&P500 Index returns $(\Delta \mathrm{SP} 500)$;

- implied volatility of one period back $\left(\Delta I V_{t-1}\right)$.

All these variables must be stationary, and the paper uses changes in the variables. The delta $(\Delta)$ represents the difference between the current and previous periods. In addition, to represent the change in connections between the two markets, dummy (D) variable cross-terms with the variables is used. When the significant coefficients are obtained from the regression, a change in the connection between the two markets is observed. The main regression is used by Konstatidini (2016) and Glatzer and Shneider (2003), thus it is replicated using the UK and US markets' instruments in the estimation. All these variables were chosen as they are used by the authors who study the predictability of asset returns.

$\Delta I V_{t}=$ const $+\beta_{1} \Delta R F+\beta_{2} \Delta E X+$

$+\beta_{3} \Delta V I X+\beta_{4} \Delta U S S L+\beta_{5} \Delta S P 500+$

$+\beta_{6} \Delta I V_{t-1}+\beta_{7} \Delta R F \cdot D+\beta_{8} \Delta E X \cdot D+$

$+\beta_{9} \Delta V I X \cdot D+\beta_{10} \Delta U S S L \cdot D+$

$+\beta_{11} \Delta S P 500 \cdot D+\beta_{12} \Delta I V_{t-1} \cdot D+\varepsilon_{t}$,

where $\Delta \mathrm{IV}_{\mathrm{t}}$ - change in implied volatility $(t-(t-1))$, $\triangle R F$ - change in the risk-free rate, $\triangle E X$ - change in the exchange rate of GBP/USD, $\triangle U S S L$ - the dif- 
ference between the long-term bond (10-Year) and short-term note, (1-Year) of the US Treasury government bond yield, $\triangle V I X$ - change in Volatility Index quoted by CBOE, $\Delta \Delta I V_{t-1}$ - change in IV in period $t-1, D$ - dummy variable "Change in connection” (0 - before Brexit; 1 - after Brexit).

Testing the model is performed in the Results section.

\section{DATA DESCRIPTION}

The daily options data of FTSE100 are chosen for this study. The data are obtained from Bloomberg Terminal, which gives access to the London Stock Exchange and the Chicago Board Options Exchange (CBOE) database. The duration of the observation is from February 1, 2016, to October 30,2016 . It is expected the structural break will exist on the market after the Brexit referendum on May 23, 2016. It means after a "breakpoint," the change in connections between two markets is estimated. As mentioned in the Methodology part, the Dummy variable is used to indicate the change in the connection. Thus, the sample is divided by 92 trading days ( 92 observations) before the Brexit referendum day and 89 trading days (89 observations) after the Brexit referendum day. The entire sample includes 181 trading days, so there are 181 observations. Every traded day includes contracts with maturities from 2 to 3 months. Options are expired every third
Friday of the month. Holidays and weekends are discarded from the sample.

The data for the regression consists of changes in implied volatilities of call option prices $\left(\Delta \mathrm{IV} \mathrm{t}_{\mathrm{t}}\right)$, changes in LIBOR rates for 2 and 3 months for the corresponding day (as a risk-free rate $(\triangle \mathrm{RF})$ ), changes in the exchange rate (Great British Pound/United States Dollar- $\triangle \mathrm{EX}$ ), change in VIX (Volatility Index) - $\triangle$ VIX, the United States Slope (the difference between 10Y and 1Y US Treasury government bonds) - USSL, and S\&P 500 Index returns ( $\Delta$ SP500).

The highest implied volatility is depicted with a value of 1.301. Figures 1 and 2 represent implied volatility. As one can see, high volatility is depicted not during the Brexit referendum in June but during October. It can be explained by the US market expectations about Presidential elections. However, the impact of this volatility is also checked, and no significant changes are seen in the estimations. Since the expectation about the Brexit referendum brings uncertainty to both political and individual companies in the market (Hill et al., 2019), it makes to depreciate the British pound against the US dollar. Thus, the mean change in the exchange rate $(\triangle \mathrm{EX})$ is negative. Thereby, the skewness is negative (right-handed skewed). In addition, kurtosis represents the tails of the distribution, which are pretty wide (24.219). This means the uncertainty is vast.

One of the most exciting findings from the data descriptive is the negative skewness of $\Delta$ SP500

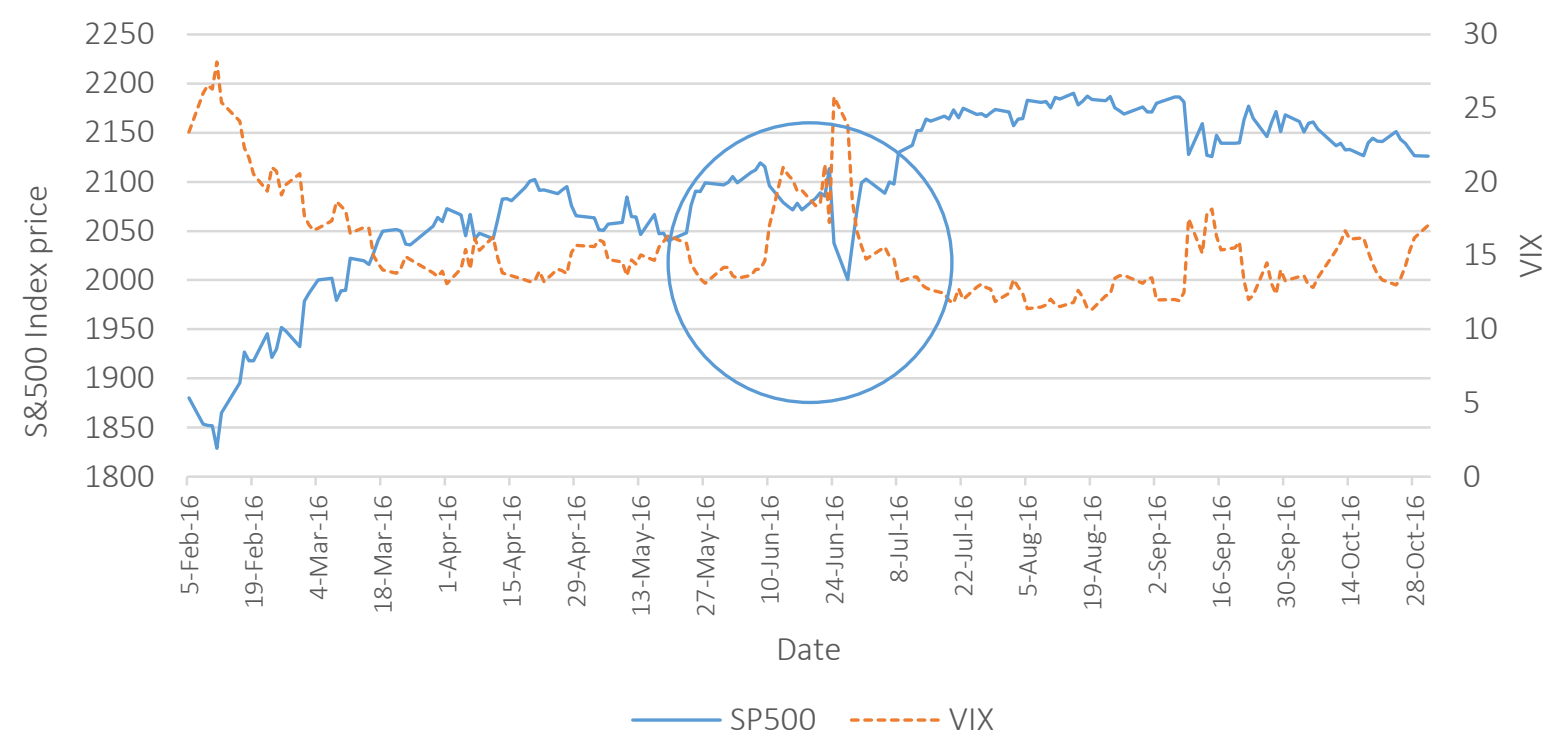

Figure 1. S\&P500 Index prices and Volatility Index (VIX) 


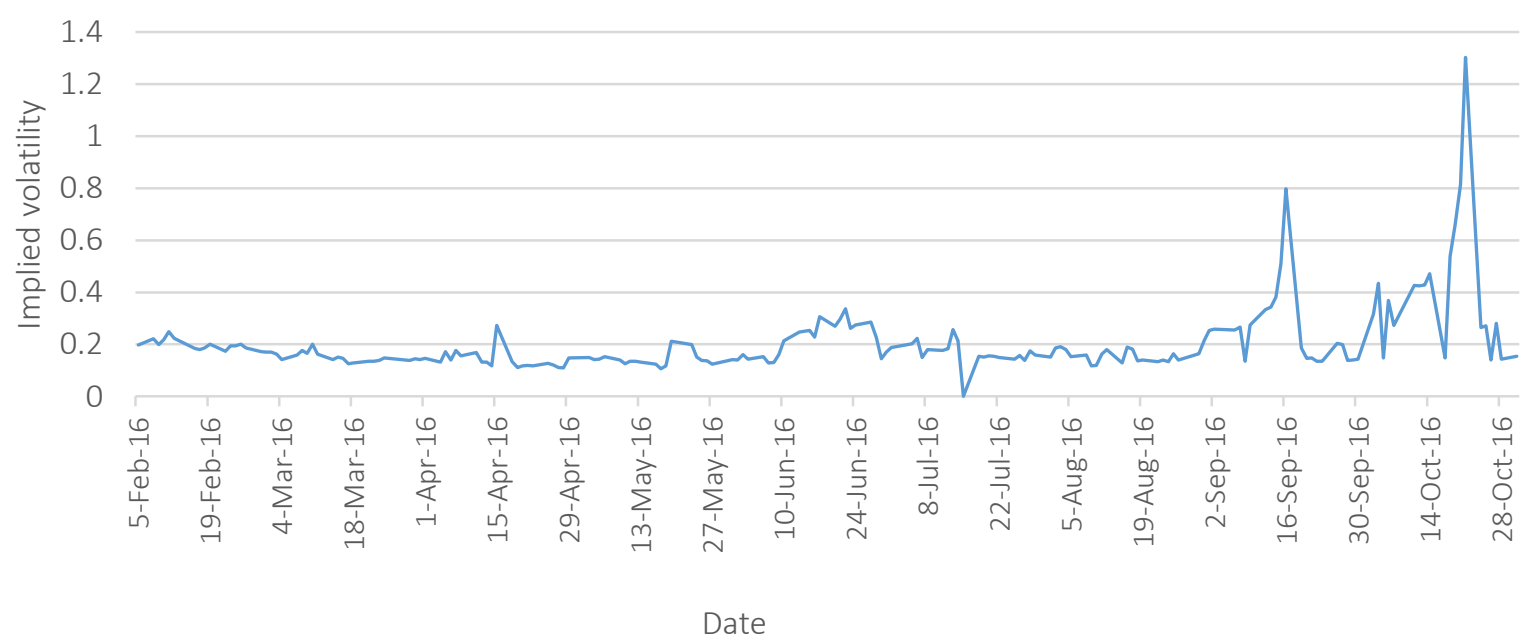

Figure 2. Implied volatility (IV) values in February - October 2016

$(-0.437)$. Usually, VIX and S\&P500 are positively correlated. However, now it is the opposite case. The Brexit referendum can explain this. The S\&P 500 Index returns fall due to the uncertainty of Brexit. The US and UK economies are part of an open economy, and market players gear up for negativity. Thus the US stock market begins to fall down even earlier than the referendum has been happening. The volatility (VIX), in turn, rocks up immediately. That is why there is a negative relationship between VIX and S\&P500 Index. At the beginning of July, the market expectation is normalized and keeps moving with a positive correlation between S\&P500 and VIX.

After the Brexit referendum, the Risk-free rate (R.F.) falls down and thus can be observed using skewness with a negative value $(-0.6)$.

\section{RESULTS}

The data used should be stationary to obtain good results. This means that the stochastic process's unconditional joint probability distribution does not change over time. In other words, the mean and variance of the variables are constant. DickeyFuller test is applicable to test the data on stationarity. The key variables on the stationarity are checked to use in the regression. These variables are: change in implied volatility, change in the exchange rate, S\&P500 index returns, change in VIX, and change in the risk-free rate. The results of stationarity are presented in Appendix A, Table
A1. When the stationarity is checked, the autoregressive vector model (VAR) is used. VAR regression gives the possibility to regress each dependent variable on lags of other dependent variables and on lags of itself. The results of VAR regression are presented in Appendix A, Table A2. These results are needed to estimate the Granger causality effect (Wald test) to understand each variable's causation. These results will help to understand the economic insights and check the endogeneity. The results of the Granger causality effect are presented in Table 1. The most interesting findings relate to the $\Delta$ VIX, which has a significant impact on the change in the Exchange rate $(\triangle \mathrm{EX})$ and on the returns of the S\&P500 Index ( $\Delta$ SP500). As mentioned above, the key goal is not to describe the cause of relationships but to understand the change in the connection between the UK and US markets. To summarize, these tests make sure that the stationary data is used (using the Dickey-Fuller test) and check the endogeneity (using Granger causality effect).

Table 2 represents the estimation results of the model. Independent variables are listed in the first column. The dependent variable is the implied volatility change estimated three times. Estimated coefficients and standard errors (in parentheses) are reported. The significance of $p$-value is labeled by stars, which indicates the corresponded confidence interval, where ${ }^{*}$ (one star) represents $p<0.1,{ }^{* *}$ (two stars) represent $p<0.05$, and ${ }^{* * *}$ (three stars) represents $p<0.01$. In addition, the Adjusted R-squared and number of observations are shown at the bottom. 
Table 1. Granger causality Wald test

\begin{tabular}{|c|c|c|c|c|}
\hline Equation & Excluded & Chi2 & df & Prob>chi2 \\
\hline$\Delta I V$ & $\Delta \mathrm{VIX}$ & 1.545 & 2 & 0.462 \\
\hline$\Delta I V$ & $\triangle S P O A$ & 1.262 & 2 & 0.532 \\
\hline$\Delta I V$ & $\triangle R F$ & 3.377 & 2 & 0.185 \\
\hline$\Delta I V$ & $\triangle E X$ & 1.258 & 2 & 0.533 \\
\hline$\Delta I \mathrm{~V}$ & $A L L$ & 6.261 & 8 & 0.618 \\
\hline$\triangle \mathrm{VIX}$ & $\Delta \mathrm{IV}$ & 1.443 & 2 & 0.486 \\
\hline$\Delta \mathrm{VIX}$ & $\triangle S P 500$ & 1.583 & 2 & 0.453 \\
\hline$\triangle \mathrm{VIX}$ & $\Delta R F$ & 1.552 & 2 & 0.460 \\
\hline$\Delta V I X$ & $\triangle E X$ & 0.765 & 2 & 0.682 \\
\hline$\Delta \mathrm{VIX}$ & $A L L$ & 7.253 & 8 & 0.510 \\
\hline$\triangle S P 500$ & $\Delta \mathrm{IV}$ & 0.442 & 2 & 0.802 \\
\hline$\triangle S P 500$ & $\Delta V I X$ & 6.242 & 2 & 0.044 \\
\hline$\triangle S P 500$ & $\Delta R F$ & 1.132 & 2 & 0.568 \\
\hline$\triangle S P 500$ & $\triangle E X$ & 0.996 & 2 & 0.608 \\
\hline$\triangle S P 500$ & ALL & 9.258 & 8 & 0.321 \\
\hline$\Delta R F$ & $\Delta \mathrm{IV}$ & 0.0006 & 2 & 0.999 \\
\hline$\triangle R F$ & $\Delta V I X$ & 0.021 & 2 & 0.989 \\
\hline$\Delta R F$ & $\triangle \mathrm{SP} 500$ & 0.072 & 2 & 0.964 \\
\hline$\Delta R F$ & $\triangle E X$ & 0.308 & 2 & 0.857 \\
\hline$\triangle R F$ & ALL & 0.368 & 8 & 0.989 \\
\hline$\Delta \mathrm{EX}$ & $\Delta \mathrm{IV}$ & 0.017 & 2 & 0.991 \\
\hline$\Delta E X$ & $\Delta \mathrm{VIX}$ & 7.614 & 2 & 0.022 \\
\hline$\Delta E X$ & $\triangle \mathrm{SP500}$ & 3.705 & 2 & 0.157 \\
\hline$\Delta E X$ & $\Delta R F$ & 1.062 & 2 & 0.588 \\
\hline$\Delta \mathrm{EX}$ & ALL & 9.813 & 8 & 0.278 \\
\hline
\end{tabular}

The first regression represents the time before the Brexit referendum, May 23, 2016. The results show that changes in $\mathrm{IV}_{\mathrm{t}-1}$ and the $\mathrm{S} \& \mathrm{P} 500$ Index returns are significant values and have an impact on $\Delta \mathrm{IV}$.

The second regression designed in the third column represents the time after the Brexit referendum, May 23, 2016. After the Brexit referendum, the LIBOR rate has been lowered; thus, it significantly affects implied volatility. The most interesting thing is that the effect of S\&P500 Index returns become insignificant. Some may ask what happened and what does it mean? To answer this question, you should appeal to investor psychology. An investor tends to invest in stable assets that can give a regular return. The UK economy is stable and relates to the developed and progressive market with strong financial institutions. When the uncertainty occurs, the investor is going to investigate the market and keep waiting for the market reaction.

Before the Brexit referendum, financial markets were more optimistic, the FTSE 100 increased, and the returns grew up to correspond. Furthermore, the GBP was depreciating since the end of 2015, British goods and services became cheaper, and the UK financial market became a dainty piece for investors, despite the potential risk of Brexit. However, when the Brexit referendum exists, the US investors became more pessimistic about the British economy, leading to the disintegration of the UK economy with the US economy. This effect is reflected in the insignificance of the S\&P500 Index returns.

Table 3 indicates the correlation relationship among variables used in the regression. The correlation between the returns of $\Delta \mathrm{VIX}$ and $\Delta \mathrm{S} \& \mathrm{P} 500$ is negative. Figure 1 depicts the increase of VIX and the decline of S\&P500 one week before and after the Brexit referendum. Moreover, there is a positive correlation between R.F. change and EX change. When the risk-free rate increases, the exchange currency pair GBP/USD also grows because the British pound becomes stronger.

The change in the risk-free rate $(\Delta \mathrm{RF})$ negatively correlates with the change in implied volatility $(\Delta \mathrm{IV})$ of the FTSE 100 Index. An increase in the risk-free rate makes it more expensive to invest, so market volatility declines. In turn, it decreases the option-implied volatility. 
Table 2. Model estimation results

\begin{tabular}{|c|c|c|c|}
\hline \multirow{2}{*}{ Variables } & Before the referendum & After the referendum & Full period \\
\hline & IV & IV & IV \\
\hline \multirow{2}{*}{$\Delta \mathrm{RF}$} & -0.228 & $-2.323 * * *$ & -0.308 \\
\hline & $(0.336)$ & $(0.567)$ & $(0.366)$ \\
\hline \multirow{2}{*}{$\Delta \mathrm{IV} \mathrm{V}_{\mathrm{t}-1}$} & $-0.222^{* *}$ & -0.307 & $-0.197^{*}$ \\
\hline & $(0.088)$ & $(0.193)$ & $(0.106)$ \\
\hline \multirow{2}{*}{$\Delta E X$} & -0.8 & -0.582 & -0.719 \\
\hline & $(2.417)$ & $(3.916)$ & $(2.57)$ \\
\hline \multirow{2}{*}{$\Delta V I X$} & 0.153 & -0.632 & 0.367 \\
\hline & $(0.345)$ & $(0.706)$ & $(0.407)$ \\
\hline \multirow{2}{*}{$\triangle U S S L$} & -0.228 & 1.09 & 0.414 \\
\hline & $(0.2)$ & $(0.867)$ & $(0.418)$ \\
\hline \multirow{2}{*}{$\triangle S P 500$} & $-8.383^{* *}$ & -8.796 & $-7.609^{*}$ \\
\hline & $(3.862)$ & $(8.579)$ & $(4.054)$ \\
\hline \multirow{2}{*}{$D_{-} \Delta R F$} & & & $-1.951^{* * *}$ \\
\hline & & & $(0.658)$ \\
\hline \multirow[b]{2}{*}{ D_s IV } & & & -0.098 \\
\hline & & & $(0.226)$ \\
\hline \multirow{2}{*}{$D_{-} \Delta E X$} & & & 0.209 \\
\hline & & & $(4.72)$ \\
\hline \multirow{2}{*}{$D_{-} \Delta \mathrm{VIX}$} & & & -0.926 \\
\hline & & & $(0.84)$ \\
\hline \multirow{2}{*}{ D_AUSSL } & & & 0.127 \\
\hline & & & $(0.117)$ \\
\hline \multirow{2}{*}{ D_ $\triangle S P 500$} & & & -1.3 \\
\hline & & & $(9.564)$ \\
\hline \multirow{2}{*}{ Constant } & 0.313 & -1.038 & -0.465 \\
\hline & $(0.239)$ & $(0.857)$ & $(0.505)$ \\
\hline Observations & 92 & 89 & 181 \\
\hline Adjust $R$-squared & 0.139 & 0.117 & 0.114 \\
\hline
\end{tabular}

Note: Dependent variable: Implied Volatility (IV) of FTSE 100 Index. Standard errors in parentheses. Significance codes: ${ }^{*} p<$ $0.1, * * p<0.05, * * * p<0.01$.

Table 3. Correlation among model variables

\begin{tabular}{|c|c|c|c|c|c|c|c|}
\hline & $\Delta \mathrm{IV}$ & $\Delta \mathrm{IV}_{\mathrm{t}-1}$ & $\Delta \mathrm{RF}$ & $\Delta \mathrm{VIX}$ & $\Delta$ USSL & $\Delta E X$ & $\triangle$ SP500 \\
\hline$\Delta \mathrm{IV}$ & 1 & & & & & & \\
\hline$\Delta \mathrm{IV}_{\mathrm{t}-1}$ & -0.263 & 1 & & & & & \\
\hline$\triangle R F$ & -0.239 & 0.064 & 1 & & & & \\
\hline$\Delta V I X$ & 0.170 & -0.138 & -0.165 & 1 & & & \\
\hline$\triangle U S S L$ & -0.034 & -0.033 & 0.066 & 0.005 & 1 & & \\
\hline$\triangle E X$ & -0.097 & 0.036 & 0.036 & -0.395 & 0.061 & 1 & \\
\hline$\triangle$ SP500 & -0.197 & 0.068 & 0.153 & -0.823 & 0.039 & 0.475 & 1 \\
\hline
\end{tabular}

\section{CONCLUSION}

This study aimed to test whether the Brexit vote changed the connection between the UK and US stock markets, measured using option-implied volatility. It has been found that the Brexit referendum is associated with the significant change in how the US stock market returns affect UK stock market expectations. Specifically, S\&P 500 returns have a negative statistically significant effect on implied volatilities before the Brexit referendum. However, there is an insignificant effect after the referendum. This change happened because of uncertainty from investors' side about the future of the UK economy and worries about business reallocations from the UK. Thus, the UK and US stock markets became less integrated in the June-October period in 2016. 
The secondary finding is that the British risk-free rate (LIBOR) started to negatively affect the implied volatility of the FTSE 100 Index after the Brexit referendum.

Providing the Dickey-Fuller test allows you to check the stationarity of data for the estimations. The results show that the variables are stationary for estimations. However, the Granger causality test shows the existing problem of variable endogeneity. Due to data limitations, there was no possibility to find appropriate instrumental variables, which is both the limitation of the findings and motivation for future research.

In addition, it has been observed that there is a negative correlation between S\&P 500 and VIX one week before and one week after the Brexit referendum, which should be studied in future research, possibly using high-frequency data.

Another direction for future research is to replicate this study, focusing on other significant unexpected events: the election of Donald J. Trump in 2016 and the COVID-19 pandemic.

\section{AUTHOR CONTRIBUTIONS}

Conceptualization: Artem Bielykh, Sergiy Pysarenko.

Data curation: Artem Bielykh.

Formal analysis: Artem Bielykh, Oleksandr Kubatko.

Funding acquisition: Sergiy Pysarenko.

Investigation: Artem Bielykh, Dong Meng Ren, Oleksandr Kubatko.

Methodology: Artem Bielykh.

Project administration: Sergiy Pysarenko.

Resources: Sergiy Pysarenko.

Software: Artem Bielykh, Sergiy Pysarenko.

Supervision: Sergiy Pysarenko.

Validation: Dong Meng Ren, Oleksandr Kubatko.

Visualization: Dong Meng Ren, Oleksandr Kubatko.

Writing - original draft: Artem Bielykh, Sergiy Pysarenko.

Writing - review \& editing: Sergiy Pysarenko, Dong Meng Ren, Oleksandr Kubatko.

\section{ACKNOWLEDGMENT}

The authors would like to thank Olesia Verchenko for critique, a KSE M.A., external defense reviewer for helpful comments.

\section{REFERENCES}

1. Aguilar, J.-P., \& Korbel, J. (2019). Simple Formulas for Pricing and Hedging European Options in the Finite Moment Log-Stable Model. Risks, 7, 36. https://doi.org/10.3390/ risks7020036

2. Aguilar, J. P., Coste, C., \& Korbel, J. (2018). Series representation of the Pricing Formula for the EuropeaN Option Driven by Space-Time Fractional Diffusion. Fractional Calculus and Applied Analysis, 21, 981-1004. https://doi.org/10.1515/ fca-2018-0054
3. Bahra, B. (1997). Implied riskneutral probability density functions from option prices: theory and application (56 p.). London, Bank of England. Retrieved from https:// papers.ssrn.com/sol3/papers. cfm?abstract_id=77429

4. Black, F., \& Scholes, M. (1973). The Pricing of Options and Corporate Liabilities. The Journal of Political Economy, 81(3), 637-654. https:// www.jstor.org/stable/1831029
5. Breeden, D., \& Litzenberger, R. (1978). Prices of state-contingent claims implicit in option prices. Journal of Business, 51(4), 621651. https://www.jstor.org/stable/2352653

6. Butler, J. S., \& Schachter, B. (1986). Unbiased estimation of the Black/ Scholes formula. Journal of Financial Economics, 15(3), 341-357. https://doi.org/10.1016/0304405X(86)90025-5 
7. Cox, J., Ross, S., \& Rubinstein M. (1976). The valuation of options for alternative stochastic processes. Journal of Financial Economics, 3(1-2). 145-146. https://doi. org/10.1016/0304-405X(76)90023-4

8. Czech, K. (2017). Extracting Market Expectations from Currency Options' Risk Reversals. Annales Universitatis Mariae CurieSkłodowska section H Oeconomia, 11, 51. (In Czech). http://dx.doi. org/10.17951/h.2017.51.6.63

9. De Ville, F., \& Siles-Brügge, G. (2019). The Impact of Brexit on EU Trade Policy. Politics and Governance, 7(3), 7-18. https://doi. org/10.17645/pag.v7i3.2102

10. Eter Carr, P., Bailey, W., Brandon, J., Brennan, M. J., Copeland, T., Galai, D., Geske, B., Grinblatt, M., Hirshleifer, D., Holden, C. W., Schwartz, E. S., Sirri, E. R., Titman, S., Torous, W. N., \& Brett (1995). The Valuation of American Exchange Options with Application to Real Options (18 p.).

11. Garrett, S. J. (2015). Introductory Numerical Methods, in Introduction to Actuarial and Financial Mathematical Methods. Retrieved from https://www.elsevier.com/books/ introduction-to-actuarial-andfinancial-mathematical-methods/ garrett/978-0-12-800156-1

12. Gemmill, G., \& Kamiyama, N. (2000). International Transmission of Option Volatility and Skewness: When you're smiling, does the whole world smile? (31 p.). London: University Business School. Retrieved from http://citeseerx.ist.psu.edu/ viewdoc/download?doi=10.1.1.194. 8769\&rep=rep $1 \&$ type $=$ pdf

13. Glatzer, E., \& Scheicher, M. (2003). Modelling the implied probability of stock market movements (39 p.). European Central Bank. Retrieved from https://ideas.repec.org/p/ecb/ ecbwps/2003212.html

14. Hassan, T. A., Hollander, S., \& van Lent L., Tahoun, A. (2019). The Global Impact of Brexit Uncertainty. TRR 266 Accounting for Transparency (Working Paper Series No. 11). http://dx.doi.org/10.2139/ ssrn.3501910

15. Hill, P., Korczak A., \& Korczak, P. (2019). Political uncertainty exposure of individual companies:
The case of the Brexit referendum. Journal of Banking \& Finance, 100 58-76. https://doi.org/10.1016/j. jbankfin.2018.12.012

16. Hohlmeier, M., \& Fahrholz, C. (2018). The Impact of Brexit on Financial Markets - Taking Stock. International Journal of Financial Studies, 6(3), 65. https://doi. org/10.3390/ijfs6030065

17. Hull, J. (2003). Options, futures, and other derivatives (896 p.). New Jersey.

18. Karoui, N., Jeanblanc-Picque, M., \& Shreve, S. E. (1998). Robustness of the Black and Scholes formula. Mathematical Finance, 8(2). 93-126. https://doi.org/10.1111/14679965.00047

19. Kartanaite, I., Kovalov, B., Kubatko O., \& Krušinskas R. (2021). Financial modeling trends for production companies in the context of Industry 4.0. Investment Management and Financial Innovations, 18(1), 270284. http://dx.doi.org/10.21511/ imfi.18(1).2021.23

20. Konstantinidi, E., Skiadopoulos, G., \& Tzagkaraki, E. (2008). Can the Evolution of Implied Volatility be Forecasted? Evidence from European and the US Implied Volatility Indices. Journal of Banking and Finance, 32(11), 2401-2411. https://doi.org/10.1016/j.jbankfin.2008.02.003

21. Kurecic, P., \& Kokotovic, F. (2018). Empirical analysis of the impact of Brexit referendum and postreferendum events on selected stock exchange indexes. The South East European Journal of Economics and Business, 13(1), 7-16. https://doi. org/10.2478/jeb-2018-0001

22. Malz, A. (1996). Using option prices to estimate realignment probabilities in the European Monetary System: the case of sterling-mar. Journal of International Money and Finance, 15(5), 717-748.

23. Melick, W., \& Tomas, C. (1997). Recovering an Asset's Implied PDF from Option Prices: An Application to Crude Oil during the Gulf Crisis. Journal of Financial and Quantitative Analysis, 32(1), 91-115. https:// doi.org/10.2307/2331318

24. Mixon, S. (2002). Factors Explaining Movements in the Implied
Volatility Surface. Journal of Futures Markets, 22(10), 915-937. http:// dx.doi.org/10.1002/fut.10039

25. Neuhaus, H. (1995). The information content of derivatives for monetary policy. Deutsche Bundesbank Economic Research Group. Retrieved from https://www. bundesbank.de/resource/blob/702 972/5a6dadf32caf5f9b5daa898f9cddc828/mL/1995-07-01-dkp-03-data. pdf

26. Phelim, P. Boyle, \& Ananthanarayanan, A. L. (1977). The impact of variance estimation in option valuation models. Journal of Financial Economics, 5(3), 375-387. https://doi. org/10.1016/0304-405X(77)90044-7

27. Pysarenko, S., Alexeev V., \& Tapon, F. (2019). Predictive blends: fundamental indexing meets Markowitz. Journal of Banking \& Finance, 100, 28-42. https://doi.org/10.1016/j. jbankfin.2018.12.016

28. Ramiah, V., Pham, H. N. A., \& Moosa, I. (2017). The sectoral effects of Brexit on the British economy: early evidence from the reaction of the stock market. Applied Economics, 49(26), 2508-2514. https://doi.org/10.1080/00036846.2 016.1240352

29. Shahzad, K., Rubbaniy, G., Lensvelt M.A.P.E., \& Tariq, B. (2019). UK's stock market reaction to Brexit process: A tale of two halves. Economic Modelling, 80, 275-283, https://doi. org/10.1016/j.econmod.2018.11.013

30. Sathyanarayana, S., \& Gargesha, S. (2016). Impact of BREXIT Referendum on Indian Stock Market. IRA-International Journal of Management \& Social Sciences, 5(1), 104-121. http://dx.doi.org/10.21013/ jmss.v5.n1.p12

31. Volk-Makarewicz, W., Borovkova, S., \& Heidergott, B. (2021). Assessing the impact of jumps in an option pricing model: A gradient estimation approach. European Journal of Operational Research. https://doi. org/10.1016/j.ejor.2021.07.015

32. Wu, H.-C. (2004). Pricing European options based on the fuzzy pattern of Black-Scholes formula. Computers \& Operations Research, 31(7), 1069-1081. https://doi.org/10.1016/ S0305-0548(03)00065-0 


\section{APPENDIX A}

\section{VECTOR AUTOREGRESSIVE MODEL RESULTS}

Table A1. Dickey-Fuller tests

\begin{tabular}{|c|c|c|c|c|c|c|c|}
\hline \multirow{2}{*}{$\begin{array}{l}\text { Dependent } \\
\text { Variables }\end{array}$} & \multicolumn{7}{|c|}{ Augmented Dickey-Fuller test for unit root } \\
\hline & $\begin{array}{l}\text { Independent } \\
\text { Variables }\end{array}$ & $\begin{array}{c}\text { Test } \\
\text { Statistics }\end{array}$ & $\begin{array}{c}\text { 1\% Critical } \\
\text { value }\end{array}$ & $5 \%$ Critical value & $10 \% \mathrm{C}$ & alue & \\
\hline \multirow[t]{6}{*}{$\triangle R F$} & $\mathrm{Z}(\mathrm{t})$ & -3.042 & -3.73 & -2.992 & \multicolumn{2}{|c|}{-2.626} & \\
\hline & $\mathrm{D} 2 . \mathrm{RF}$ & Coef. & Std. Err & $t$ & $P>t$ & \multicolumn{2}{|c|}{ [95\% Conf. Interval] } \\
\hline & LD. & -1.979 & 0.650 & -3.04 & 0.006 & -3.322 & -0.636 \\
\hline & LD2. & 0.270 & 0.510 & 0.53 & 0.602 & -0.783 & 1.323 \\
\hline & L2D2. & 0.014 & 0.231 & 0.06 & 0.950 & -0.463 & 0.493 \\
\hline & cons & -0.011 & 0.008 & -1.25 & 0.225 & -0.029 & 0.007 \\
\hline \multirow[t]{6}{*}{$\Delta \mathrm{IV}$} & $\mathrm{Z}(\mathrm{t})$ & -5.033 & -3.73 & -2.992 & \multicolumn{2}{|c|}{-2.626} & \\
\hline & D2.RF & Coef. & Std. Err & t & $P>t$ & \multicolumn{2}{|c|}{ [95\% Conf. Interval] } \\
\hline & LD. & -2.778 & 0.552 & -5.03 & 0 & -3.918 & -1.639 \\
\hline & LD2. & 0.682 & 0.409 & 1.67 & 0.108 & -0.162 & 1.527 \\
\hline & $\mathrm{L} 2 \mathrm{D} 2$. & 0.274 & 0.175 & 1.56 & 0.132 & -0.088 & 0.636 \\
\hline & cons & 0.112 & 0.067 & 1.66 & 0.11 & -0.027 & 0.253 \\
\hline \multirow[t]{6}{*}{$\triangle S \& P 500$} & $z(t)$ & -4.066 & -3.73 & -2.992 & \multicolumn{2}{|c|}{-2.626} & \\
\hline & D2.RF & Coef. & Std. Err & t & $P>t$ & \multicolumn{2}{|c|}{ [95\% Conf. Interval] } \\
\hline & LD. & -3.099 & 0.762 & -4.07 & 0 & -4.672 & -1.526 \\
\hline & LD2. & 0.622 & 0.534 & 1.16 & 0.256 & -0.481 & 1.727 \\
\hline & $\mathrm{L} 2 \mathrm{D} 2$. & 0.242 & 0.232 & 1.05 & 0.306 & -0.236 & 0.722 \\
\hline & cons & -0.003 & 0.001 & -1.55 & 0.134 & -0.007 & 0.0009 \\
\hline \multirow[t]{6}{*}{$\Delta \mathrm{VIX}$} & $\mathrm{Z}(\mathrm{t})$ & -3.838 & -3.73 & -2.992 & \multicolumn{2}{|c|}{-2.626} & \\
\hline & $\mathrm{D} 2 . \mathrm{RF}$ & Coef. & Std. Err & $\mathrm{T}$ & $P>t$ & \multicolumn{2}{|c|}{ [95\% Conf. Interval] } \\
\hline & LD. & -2.845 & 0.741 & -3.84 & 0.001 & -4.375 & -1.315 \\
\hline & LD2. & 0.433 & 0.529 & 0.82 & 0.421 & -0.659 & 1.527 \\
\hline & L2D2. & 0.216 & 0.253 & 0.85 & 0.401 & -0.306 & 0.740 \\
\hline & cons & 0.020 & 0.020 & 1.02 & 0.316 & -0.020 & 0.061 \\
\hline \multirow[t]{6}{*}{$\triangle E X$} & $Z(t)$ & -2.29 & -3.73 & -2.992 & \multicolumn{2}{|c|}{-2.626} & \\
\hline & D2.RF & Coef. & Std. Err & $\mathrm{t}$ & $P>t$ & \multicolumn{2}{|c|}{ [95\% Conf. Interval] } \\
\hline & L1. & -2.394 & 1.045 & -2.29 & 0.032 & -4.558 & -0.231 \\
\hline & LD. & 0.992 & 0.925 & 1.07 & 0.295 & -0.922 & 2.908 \\
\hline & L2D. & 0.749 & 0.542 & 1.38 & 0.18 & -0.372 & 1.871 \\
\hline & _cons & -0.0047 & 0.003 & -1.49 & 0.15 & -0.011 & 0.001 \\
\hline
\end{tabular}


Table A2. Vector autoregressive model results

\begin{tabular}{|c|c|c|c|c|c|c|c|}
\hline Equation & \multicolumn{2}{|r|}{ Parms } & RMSE & $R$-sq & \multicolumn{2}{|c|}{ chi2 } & P > chi2 \\
\hline IV & \multicolumn{2}{|r|}{11} & 0.314078 & 0.1123 & \multicolumn{2}{|c|}{13.15594} & 0.2151 \\
\hline VIX & \multicolumn{2}{|r|}{11} & 0.089148 & 0.0803 & \multicolumn{2}{|c|}{9.083468} & 0.5242 \\
\hline SP500 & \multicolumn{2}{|r|}{11} & 0.007444 & 0.0921 & \multicolumn{2}{|c|}{10.5491} & 0.3937 \\
\hline RF & & 11 & 0.043313 & 0.131 & \multicolumn{2}{|c|}{15.67705} & 0.1093 \\
\hline \multicolumn{2}{|l|}{ EX } & 11 & 0.010347 & 0.11 & & & 0.1744 \\
\hline & & & egression & of VAR $n$ & & & \\
\hline Variab & & Coef. & Sd.er. & z & $P>|z|$ & $95 \% \mathrm{c}$ & Interval \\
\hline IV & IV & & & & & & \\
\hline & L1. & -0.192 & 0.087 & -2.200 & 0.028 & -0.363 & -0.021 \\
\hline & L2. & 0.074 & 0.088 & 0.840 & 0.400 & -0.099 & 0.248 \\
\hline & VIX & & & & & & \\
\hline & L1. & 0,933 & 0,899 & 1,040 & 0,299 & $-0,829$ & 2,695 \\
\hline & L2. & -0.528 & 0.695 & -0.760 & 0.448 & -1.889 & 0.834 \\
\hline & SP500 & & & & & & \\
\hline & L1. & 4.144 & 8.961 & 0.460 & 0.644 & -13.419 & 21.707 \\
\hline & L2. & -7.449 & 7.316 & -1.020 & 0.309 & -21.787 & 6.890 \\
\hline & RF & & & & & & \\
\hline & L1. & 0.452 & 0.721 & 0.630 & 0.531 & -0.961 & 1.864 \\
\hline & L2. & 1.465 & 0.797 & 1.840 & 0.066 & -0.098 & 3.028 \\
\hline & EX & & & & & & \\
\hline & L1. & 4.373 & 4.196 & 1.040 & 0.297 & -3.850 & 12.596 \\
\hline & L2. & 1.882 & 3.886 & 0.480 & 0.628 & -5.734 & 9.498 \\
\hline & cons & 0.079 & 0.032 & 2.420 & 0.015 & 0.015 & 0.142 \\
\hline VIX & & & & & & & \\
\hline & IV & & & & & & \\
\hline & L1. & -0.030 & 0.025 & -1.200 & 0.230 & -0.078 & 0.019 \\
\hline & L2. & -0.008 & 0.025 & -0.300 & 0.761 & -0.057 & 0.042 \\
\hline & VIX & & & & & & \\
\hline & L1. & -0.128 & 0.255 & -0.500 & 0.615 & -0.629 & 0.372 \\
\hline & L2. & 0.373 & 0.197 & 1.890 & 0.059 & -0.013 & 0.759 \\
\hline & SP500 & & & & & & \\
\hline & L1. & 0.069 & 2.544 & 0.030 & 0.978 & -4.916 & 5.054 \\
\hline & L2. & 2.613 & 2.076 & 1.260 & 0.208 & -1.457 & 6.683 \\
\hline & RF & & & & & & \\
\hline & L1. & 0.248 & 0.205 & 1.210 & 0.225 & -0.153 & 0.649 \\
\hline & L2. & 0.160 & 0.226 & 0.710 & 0.479 & -0.283 & 0.604 \\
\hline & EX & & & & & & \\
\hline & L1. & 0.578 & 1.191 & 0.490 & 0.627 & -1.756 & 2.913 \\
\hline & L2. & 0.837 & 1.103 & 0.760 & 0.448 & -1.325 & 2.998 \\
\hline & cons & -0.009 & 0.009 & -0.990 & 0.324 & -0.027 & 0.009 \\
\hline SP500 & & & & & & & \\
\hline & IV & & & & & & \\
\hline & L1. & 0.001 & 0.002 & 0.320 & 0.745 & -0.003 & 0.005 \\
\hline & L2. & -0.001 & 0.002 & -0.490 & 0.624 & -0.005 & 0.003 \\
\hline & VIX & & & & & & \\
\hline & L1. & 0,005 & 0,021 & 0,210 & 0,830 & $-0,037$ & 0,046 \\
\hline & L2. & -0.041 & 0.016 & -2.500 & 0.012 & -0.073 & -0.009 \\
\hline & SP500 & & & & & & \\
\hline & L1. & -0.105 & 0.212 & -0.500 & 0.620 & -0.522 & 0.311 \\
\hline & L2. & -0.283 & 0.173 & -1.630 & 0.103 & -0.623 & 0.057 \\
\hline & $\mathrm{RF}$ & & & & & & \\
\hline & L1. & -0.016 & 0.017 & -0.920 & 0.358 & -0.049 & 0.018 \\
\hline & L2. & -0.016 & 0.019 & -0.840 & 0.402 & -0.053 & 0.021 \\
\hline & EX & & & & & & \\
\hline & L1. & -0.052 & 0.099 & -0.520 & 0.600 & -0.247 & 0.143 \\
\hline & L2. & -0.081 & 0.092 & -0.880 & 0.377 & -0.262 & 0.099 \\
\hline & cons & 0.001 & 0.001 & 1.690 & 0.091 & 0.000 & 0.003 \\
\hline
\end{tabular}


Table A2 (cont.). Vector autoregressive model results

\begin{tabular}{|c|c|c|c|c|c|c|c|}
\hline \multicolumn{8}{|c|}{ Regression results of VAR model } \\
\hline \multicolumn{2}{|c|}{ Variables } & \multirow[t]{2}{*}{ Coef. } & \multirow[t]{2}{*}{ Sd.er. } & \multirow[t]{2}{*}{$\mathbf{z}$} & \multirow[t]{2}{*}{$P>|z|$} & \multicolumn{2}{|c|}{ 95\% conf. Interval } \\
\hline $\mathrm{RF}$ & & & & & & & \\
\hline & IV & & & & & & \\
\hline & L1. & 0.000 & 0.012 & 0.000 & 1.000 & -0.024 & 0.024 \\
\hline & L2. & 0.000 & 0.012 & -0.030 & 0.980 & -0.024 & 0.024 \\
\hline & VIX & & & & & & \\
\hline & L1. & -0.018 & 0.124 & -0.150 & 0.884 & -0.261 & 0.225 \\
\hline & L2. & 0.001 & 0.096 & 0.010 & 0.994 & -0.187 & 0.188 \\
\hline & SP500 & & & & & & \\
\hline & L1. & -0.292 & 1.236 & -0.240 & 0.813 & -2.714 & 2.130 \\
\hline & L2. & 0.128 & 1.009 & 0.130 & 0.899 & -1.850 & 2.105 \\
\hline & RF & & & & & & \\
\hline & L1. & -0.356 & 0.099 & -3.590 & 0.000 & -0.551 & -0.162 \\
\hline & L2. & -0.234 & 0.110 & -2.130 & 0.033 & -0.450 & -0.019 \\
\hline & EX & & & & & & \\
\hline & L1. & 0.321 & 0.579 & 0.560 & 0.579 & -0.813 & 1.455 \\
\hline & L2. & 0.010 & 0.536 & 0.020 & 0.986 & -1.041 & 1.060 \\
\hline & cons & -0.002 & 0.004 & -0.360 & 0.722 & -0.010 & 0.007 \\
\hline \multicolumn{8}{|l|}{ EX } \\
\hline & IV & & & & & & \\
\hline & L1. & 0.000 & 0.003 & 0.100 & 0.922 & -0.005 & 0.006 \\
\hline & L2. & 0.000 & 0.003 & -0.060 & 0.949 & -0.006 & 0.006 \\
\hline & VIX & & & & & & \\
\hline & L1. & 0.048 & 0.030 & 1.630 & 0.103 & -0.010 & 0.106 \\
\hline & L2. & -0.054 & 0.023 & -2.340 & 0.019 & -0.098 & -0.009 \\
\hline & SP500 & & & & & & \\
\hline & L1. & 0.204 & 0.295 & 0.690 & 0.490 & -0.375 & 0.782 \\
\hline & L2. & -0.431 & 0.241 & -1.790 & 0.074 & -0.903 & 0.041 \\
\hline & $\mathrm{RF}$ & & & & & & \\
\hline & L1. & -0.023 & 0.024 & -0.990 & 0.323 & -0.070 & 0.023 \\
\hline & L2. & -0.017 & 0.026 & -0.630 & 0.525 & -0.068 & 0.035 \\
\hline & EX & & & & & & \\
\hline & L1. & -0.230 & 0.138 & -1.670 & 0.096 & -0.501 & 0.041 \\
\hline & L2. & -0.086 & 0.128 & -0.670 & 0.500 & -0.337 & 0.165 \\
\hline & cons & 0.000 & 0.001 & -0.160 & 0.877 & -0.002 & 0.002 \\
\hline
\end{tabular}

